\title{
INTERFERÊNCIA DE CAPIM-MARMELADA NA CULTURA DA SOJA ${ }^{1}$
}

\author{
DAGOBERTO MARTINS ${ }^{2}$
}

\begin{abstract}
Com o objetivo de estudar os efeitos de diferentes períodos de controle e convivência de plantas daninhas sobre o crescimento e produção da soja (Glycine max), variedade OCEPAR 4 - Iguaçu, foi instalado e conduzido a presente pesquisa em Cascavel/PR, em um latossolo roxo distrófico. O delineamento experimental utilizado foi o de blocos casualizados, com três repetições. Os tratamentos foram dispostos em dois grupos: no primeiro, a cultura foi mantida livre da comunidade infestante desde a emergência da cultura até 0 , $10,20,30,40,50,60,70,80,90$ e 100 dias de seu ciclo, após o qual as plantas daninhas foram deixadas crescer livremente e, no segundo, a cultura foi mantida no mato por períodos equivalentes ao primeiro grupo, após o qual foi mantida no
\end{abstract}

RESUMO limpo. Capim-marmelada (Brachiaria plantaginea) foi a principal planta daninha da área experimental, originando a quase a totalidade da matéria seca da comunidade infestante. O estande, o número de vagens por planta, o tamanho de vagens, a altura de inserção de primeira vagem e o rendimento de grãos foram afetados pela interferência da comunidade infestante. O período total de prevenção da interferência (PTPI) e o período anterior a interferência (PAI) sobre a produtividade da cultura foram de 20 e 30 dias respectivamente, a partir da emergência da soja.

Palavras-chave: Competição, interferência, matointerferência, Brachiaria plantaginea, Glycine max.

\section{ABSTRACT}

\section{Alexandergrass interference in soybean}

The objective of this trial, carried out in Cascavel (PR), Brazil, was to study the weed competition period over some productives parameters of soybean (Glycine max). The experimental design used was the randomized complete block with three replications and the treatments were divided into two groups: in the first the crop was maintained free of weed competition and in the second it one was maintained in weed competition. The periods extensions studied were $0,10,20$, $30,40,50,60,70,80,90$ and 100 days after soybeans

\section{INTRODUÇÃO}

A interferência das plantas daninhas nas culturas agrícolas é determinada por uma série de fatores do ambiente que direta ou indiretamente influenciam o seu crescimento,

1 Recebido para publicação em 05/04/94 e na forma revisada em 30/12/94 2 2 Professor Assistente, Doutor, FCA/UNFSP, Caixa Postal 237, Botucatu, SP $18603-970$ emergence to two groups. Alexandergrass (Brachiaria plantaginea) was the most important weed of experimental area. The weed community affected most of the parameters in studied crop. Soybeans had to be maintained weed interference free for 20 days and could be in weed interference for 30 days after soybeans emergence to prevent yield loss.

Additional index words: Competition, critical periods of interference, interespecific competition, Brachiaria plantaginea, Glycine max.

desenvolvimento e produtividade. Os fatores diretos (competição, alelopatia e interferência na colheita) e os indiretos (hospedando pragas e doenças) são determinantes nas relações de interferência entre a planta cultivada e a comunidade infestante (Pitelli, 1985).

Os estudos de matocompetição na cultura da soja procuram avaliar os fatores ligados à cultura, como o cultivar (Durigan et al., 1983 e Murdock et al., 1986), o espaçamento (Jordan, 1985 e Chitapong, 1986) e a densidade (Hower \& Oliver, 1987 e Carvalho, 1993); os fatores ligados à comuni- 
dade infestante, como a espécie (Chemale \& Fleck, 1982 e Hower \& Oliver, 1987), a densidade (Eaton et al., 1973; Chemale \& Fleck, 1982 e Wyse et al., 1986) e a distribuição (Eaton et al., 1973 e Henry \& Bauman, 1987) e os fatores relacionados ao ambiente (Blanco et al., 1973; Oliver, 1979; Durigan et al., 1983; Jackson et al., 1985 e Velini \& Pitelli, 1991).

Com relação à época e duração da convivência entre a planta cultivada e a comunidade infestante, Pitelli \& Durigan (1984) denominaram de período anterior à interferência (PAI) o período, a partir da semeadura ou da emergência da cultura, no qual a cultura pode conviver com as plantas daninhas sem que ocorram reduções na produtividade. Os autores denominaram de período total de prevenção da interferência (PTPI) o periodo, a partir da semeadura ou da emergência da cultura, no qual as plantas daninhas devem ser controladas para que a cultura manifeste todo o seu potencial produtivo.

Um número considerável de trabalhos a campo vem sendo realizados no Brasil na área de matocompetição, contudo a grande maioria envolve comunidades infestantes diversificadas (Branco et al., 1973; Garcia et al.,1981; Durigan et al., 1983; Rossi, 1985 e Velini \& Pitelli, 1991). Com a utilização de práticas mais eficazes de controle, tanto químicas como culturais, aliados à monocultura, as comunidades infestantes estão tornando-se menos diversificadas, modificando as relações de interferência. Sob este aspecto, $B$. plantaginea é uma espécie daninha que vem destacando-se em áreas tradicionais de produção de soja como o Oeste do Estado do Paraná. Sua agressividade é devido, entre outros fatores, à grande produção de dissemínulos, à germinação distribuida ao longo do ciclo da cultura e à sua morfologia que leva à formação de um dossel vigoroso de folhas acima da soja.

Faz-se importante conhecer o comportamento da cultura da soja numa relação de interferência composta basicamente por $B$. plantaginea, em condições de campo. Desta forma, o presente trabalho visa determinar os efeitos de diferentes periodos de controle e de convivência de uma comunidade infestante quase que totalmente monoespecífica, sobre alguns parâmetros de crescimento e produtivos da cultura da soja.

\section{MATERIAL E MÉTODOS}

O experimento foi instalado e conduzido em Cascavel/ PR, na estação experimental da OCEPAR-pesquisa, em um Latossolo Roxo distrófico, textura argilosa, no ano agrícola de 1989/90.

O delineamento experimental adotado foi o de blocos casualizados, com três repetições. Os tratamentos foram dispostos em dois grupos. No primeiro, a cultura da soja foi mantida livre das plantas daninhas desde a emergência até 0 , 10, 20, 30, 40, 50, 60, 70, 80, 90 e 100 dias de seu ciclo, após o qual as plantas daninhas foram deixadas crescer livremente. No segundo grupo, a cultura foi mantida em convívio com as plantas daninhas por periodos equivalentes ao primeiro grupo, após o qual era mantida no limpo. O início de cada período de convivência, ou controle das plantas daninhas, foi estipulado a partir da emergência de mais de $75 \%$ das plântulas de soja, que ocorreu uma semana após a semeadura.

Cada parcela foi composta por oito linhas de semeadura espaçadas de $0,5 \mathrm{~m}$ entre si e com $5 \mathrm{~m}$ de comprimento. Considerou-se as seis linhas centrais da parcela como sendo a área útil, onde desconsiderou-se $0,5 \mathrm{~m}$ de cada extre midade. A semeadura foi realizada no segundo decêndio de novembro, utilizando-se a variedade OCEPAR 4 -Iguaçu com uma adubação de plantio de $300 \mathrm{~kg} / \mathrm{ha}$ da fórmula 0-30-10.

Nas parcelas do segundo grupo de tratamentos, onde a cultura permaneceu periodos iniciais no mato, colheu-se, ao final de cada período respectivo, as plantas daninhas de uma área de $0,5 \mathrm{~m}^{2}$ (duas sub-amostras de $0,25 \mathrm{~m}^{2}$ ), as quais foram contadas, identificadas e secas em estufa de circulação forçada de ar a $65-70^{\circ} \mathrm{C}$ até peso constante, sendo posteriormente pesadas em balança de precisão. No primeiro grupo de tratamentos, onde propunha-se estudar a extensão do período total de prevenção das interferências, o mesmo procedimento foi realizado por ocasião da colheita da cultura, no terceiro decêndio de março. O controle das plantas daninhas foi efetuado através de capinas manuais, uso de enxada nas entrelinhas e monda nas linhas.

Das seis linhas da área útil, uma linha lateral foi utilizada para retirar-se 10 plantas de soja, aos 100 dias do ciclo da cultura, para obter-se o peso de maté ria seca da parte aérea. O rendimento de grãos e o estande foi obtido utilizando-se as cinco linhas restantes $\left(10 \mathrm{~m}^{2}\right)$ da área útil. Através de 20 plantas de soja por parcela, foram avaliados a altura de plantas, a altura de inserção da primeira vagem e o número de vagens por planta. Ainda, foi tomada uma amostra de 200 vagens de cada parcela, as quais foram separadas por classe de tamanho, de acordo com o número de sementes.

Os dados coletados foram submetidos a análise de variância pelo Teste $\mathrm{F}$ e as médias dos tratamentos foram comparadas pelo Teste de Tukey $(\mathrm{P}>0,05)$.

\section{RESULTADOS E DISCUSSÃO}

As plantas daninhas que ocorreram na área experimental foram Brachiaria plantaginea (capim-marmelada), Raphanus raphanistrum (nabiça) e Bidens pilosa (picãopreto). O picão-preto ocorreu de forma muito reduzida e apenas no início do ciclo da cultura, nas parcelas mantidas no mato. Os seus poucos representantes não acumularam matéria seca suficiente para sua determinação.

Comportamento semelhante foi observado para a nabiça, onde um controle por 10 dias ou um convívio por 40 dias com a comunidade infestante e com a cultura, determinaram o seu desaparecimento por completo da área experimental, devido principalmente à supressão exercida pelo capim-marmelada. $\mathrm{O}$ acúmulo de matéria seca obtido pelas plantas de nabiça foram irrizórios se comparados ao capim-marmelada (Tabela 1).

O capim-marmelada foi a principal planta daninha da área experimental. Dela resultou a quase totalidade da matéria seca acumulada pela comunidade infestante durante o ciclo da cultura e $100 \%$ por ocasião da colheita (Tabela 1). 
TABELA 1 - Efeito de diferentes períodos de controle ou convivência das plantas daninhas sobre o número de plantas e acúmulo de matéria seca na parte aérea de $B$. plantaginea e $R$. raphanistrum e o peso de matéria seca da parte aérea de plantas de soja. Cascavel, 1989/90. Média de 3 repetiçỏes.

\begin{tabular}{|c|c|c|c|c|c|}
\hline Tratamento & $\begin{array}{c}\text { Número de } \\
\text { plantas BRAPL }\end{array}$ & $\begin{array}{l}\text { Peso de matéria } \\
\text { seca BRAPL(g) }\end{array}$ & $\begin{array}{c}\text { Número de } \\
\text { plantas RAPRA }\end{array}$ & $\begin{array}{l}\text { Peso de matéria } \\
\text { seca RAPRA(g) }\end{array}$ & $\begin{array}{l}\text { Peso de matéria } \\
\text { seca GLXMA(g) }\end{array}$ \\
\hline \multicolumn{6}{|l|}{ Dias Livre do mato } \\
\hline 1. 0 dias (test.mato) & $68,3 \mathrm{C}$ & $440,0 \mathrm{~A}$ & $0,0 \mathrm{C}$ & $0,0 \mathrm{~B}$ & $73,3 \mathrm{D}$ \\
\hline 2. 10 dias & $32,0 \mathrm{C}$ & $125,8 \mathrm{DEF}$ & $0,0 \mathrm{C}$ & $0,0 \mathrm{~B}$ & $140,0 \mathrm{ABC}$ \\
\hline 3. 20 dias & $13,7 \mathrm{C}$ & $9,8 \mathrm{G}$ & $0,0 \mathrm{C}$ & $0,0 \mathrm{~B}$ & $153,3 \mathrm{ABC}$ \\
\hline 4. 30 dias & $1,4 \mathrm{C}$ & $0,1 \mathrm{G}$ & $0,0 \mathrm{C}$ & $0,0 \mathrm{~B}$ & $168,0 \mathrm{~A}$ \\
\hline 5. 40 dias & $1,4 \mathrm{C}$ & $0,0 \mathrm{G}$ & $0,0 \mathrm{C}$ & $0,0 \mathrm{~B}$ & $160,0 \mathrm{~A}$ \\
\hline 6. 50 dias & $0,0 \mathrm{C}$ & $0,0 \mathrm{G}$ & $0,0 \mathrm{C}$ & $0,0 \mathrm{~B}$ & $177,7 \mathrm{~A}$ \\
\hline 7. 60 dias & $0,0 \mathrm{C}$ & $0,0 \mathrm{G}$ & $0,0 \mathrm{C}$ & $0,0 \mathrm{~B}$ & $160,0 \mathrm{~A}$ \\
\hline 8. 70 dias & $0,0 \mathrm{C}$ & $0,0 \mathrm{G}$ & $0,0 \mathrm{C}$ & $0,0 \mathrm{~B}$ & $156,7 \mathrm{AB}$ \\
\hline 9. 80 dias & $0,0 \mathrm{C}$ & $0,0 \mathrm{G}$ & $0,0 \mathrm{C}$ & $0,0 \mathrm{~B}$ & $153,3 \mathrm{ABC}$ \\
\hline 10. 90 dias & $0,0 \mathrm{C}$ & $0,0 \mathrm{G}$ & $0,0 \mathrm{C}$ & $0,0 \mathrm{~B}$ & $146,7 \mathrm{ABC}$ \\
\hline 11. 100 dias & $0,0 \mathrm{C}$ & $0,0 \mathrm{G}$ & $0,0 \mathrm{C}$ & $0,0 \mathrm{~B}$ & $140,0 \mathrm{ABC}$ \\
\hline \multicolumn{6}{|l|}{ Dias de convívio com mato } \\
\hline 12. 0 dias (test.limpo) & $0,0 \mathrm{C}$ & $0,0 \mathrm{G}$ & $0,0 \mathrm{C}$ & $0,0 \mathrm{~B}$ & $163,3 \mathrm{~A}$ \\
\hline 13. 10 dias & $109,7 \mathrm{BC}$ & $0,8 \mathrm{G}$ & $35,3 \mathrm{~A}$ & $0,3 \mathrm{~B}$ & $166,7 \mathrm{~A}$ \\
\hline 14. 20 dias & $239,0 \mathrm{AB}$ & $8,0 \mathrm{G}$ & 21,3 B & $1,0 \mathrm{~B}$ & $166,3 \mathrm{~A}$ \\
\hline 15. 30 dias & $288,7 \mathrm{AB}$ & $19,7 \mathrm{FG}$ & $18,0 \mathrm{~B}$ & $3,9 \mathrm{~A}$ & $163,3 \mathrm{~A}$ \\
\hline 16. 40 dias & $134,0 \mathrm{BC}$ & $56,0 \mathrm{FG}$ & $1,3 \mathrm{C}$ & $0,0 \mathrm{~B}$ & $153,3 \mathrm{ABC}$ \\
\hline 17. 50 dias & $77,0 \mathrm{C}$ & $114,8 \mathrm{EFG}$ & $0,0 \mathrm{C}$ & $0,0 \mathrm{~B}$ & $133,3 \mathrm{ABC}$ \\
\hline 18. 60 dias & $69,0 \mathrm{C}$ & $157,0 \mathrm{DE}$ & $0,0 \mathrm{C}$ & $0,0 \mathrm{~B}$ & $133,3 \mathrm{ABC}$ \\
\hline 19. 70 dias & $75,7 \mathrm{C}$ & $233,3 \mathrm{CD}$ & $0,0 \mathrm{C}$ & $0,0 \mathrm{~B}$ & $106,7 \mathrm{BCD}$ \\
\hline 20. 80 dias & $48,7 \mathrm{C}$ & $283,3 \mathrm{BC}$ & $0,0 \mathrm{C}$ & $0,0 \mathrm{~B}$ & $103,3 \mathrm{CD}$ \\
\hline 21. 90 dias & $39,0 \mathrm{C}$ & $454,9 \mathrm{~A}$ & $0,0 \mathrm{C}$ & $0,0 \mathrm{~B}$ & 73,3 D \\
\hline 22. 100 dias & $41,7 \mathrm{C}$ & $379,2 \mathrm{AB}$ & $0,0 \mathrm{C}$ & $0,0 \mathrm{~B}$ & $76,7 \mathrm{D}$ \\
\hline F. Bloco & $1,67^{\mathrm{ns}}$ & $0,96^{\mathrm{ns}}$ & $1,08^{\mathrm{ns}}$ & $1,85^{\mathrm{ns}}$ & $1,24^{\mathrm{ns}}$ \\
\hline F. Tratamento & $9,61^{* *}$ & $51,62^{* *}$ & $41,59^{\circ *}$ & $17,72{ }^{* *}$ & $11,39^{* *}$ \\
\hline C.V. $(\%)$ & 77,5 & 35,7 & 71,3 & 139,1 & 11,8 \\
\hline d.m.s. & 136,8 & 116,3 & 7,7 & 1,1 & 51,8 \\
\hline
\end{tabular}

Médias seguidas da mesma letra, não diferem estatisticamente entre si, pelo teste de Tukey $(\mathrm{P}>0,05)$.

BRAPL - Brachiaria plantaginea RAPRA - Raphanus raphanistrum GLXMA - Gbcine max

test. - testemunha

C.V. - coeficiente de variaçăo

d.m.s. - diferença mínima significativa

ns - nāo significativo

* - significativo ao nível de $1 \%$ de probabilidade

O controle por 30 dias do mato reduziu drasticamente o número de plantas de $B$. plantaginea e seu acúmulo de matéria seca, chegando à eliminação quase total das plantas. $\mathrm{O}$ aumento dos períodos de convívio da cultura com o mato levou a um incremento no peso de matéria seca do capim- marmelada e a uma redução no número de plantas a partir dos 40 dias. Aos 30 dias após a emergência da cultura encontrou-se o maior número de plantas de capim-marmelada. $\mathrm{O}$ maior acúmulo de matéria seca foi observado apenas entre os $90^{\circ}$ e $100^{\circ}$ dias. 
Coelho et al. (1991), ao trabalharem com uma comunidade infestante diversificada, observaram que o número máximo de plantas daninhas $/ \mathrm{m}^{2}$ ocorreu também aos 30 dias, porém o máximo acúmulo de matéria seca ocorreu aos 60 dias, após o que, o capim-marmelada passou a predominar na área.

O acúmulo de matéria seca observado neste trabalho assemelha-se ao observado por Rossi (1985) (entre o $30^{\circ} \mathrm{e}$ $80^{\circ}$ dias) e por Velini \& Pitelli (1991) (entre o $30^{\circ}$ e $100^{\circ}$ dias do ciclo da cultura da soja).

Rossi (1985) observou que as densidades de plantas das várias espécies estudadas mantiveram-se praticamente constante das primeiras avaliações até o final do ciclo da cultura. Coelho et al. (1988) observaram que tanto a densidade como o acúmulo de matéria seca de uma comunidade infestante diversificada cresceram por um longo período, até 75 dias do ciclo da cultura.

O esperado seria que ocorresse redução na densidade de plantas da comunidade infestante e aumento no acúmulo de maté ria seca no decor rer do ciclo da cultura, pois os fatores do meio como luz, espaço, nutrientes e água tornamse limitantes, levando à competição intraespecífica, com morte dos indivíduos menos aptos e um desenvolvimento mais vigoroso dos sobreviventes.

A densidade de plantas de uma comunidade infestante está relacionada também com o banco de propágulos do solo que, sob ação dos fatores ambientais, responde de maneira diferenciada quanto a dormência das sementes (Nogushi, 1983 e Martins \& Silva, 1994).

Nota-se, na Tabela 01, que um período de 10 dias com a cultura no limpo foi suficiente para que o acúmulo de matéria seca nas plantas de soja fosse semelhante à testemunha no limpo.

Contudo, houve a necessidade de manter-se a soja em convivência com a comunidade infestante por 70 dias ou mais para que o acúmulo de matéria seca em suas plantas decrescesse aos patamares encontrados na testemunha mantida no mato. Velini \& Pitelli (1991) também encontraram decréscimos significativos no acúmulo de matéria seca nas plantas de soja, quando houve um convívio com a comunidade infestante por mais de 60 dias.

O controle das plantas daninhas por um período de 10 dias foi suficiente para ter-se uma quantidade de vagens por planta semelhante à testemunha mantida no limpo (Tabela 2), porém com uma produção de grãos inferior à testemunha no limpo (Tabela 03).

O número de vagens por planta foi inferior à testemunha mantida no limpo quando a cultura conviveu com o mato por um período de 60 dias ou mais. Todavia, a produção de grãos da cultura da soja foi reduzida já a partir de 40 dias de convívio com o mato. A interferência das plantas daninhas sobre o número de vagens por planta ocorre comumente (Eaton et al., 1973; Durigan et al., 1983; Rossi, 1985; Wyse et al., 1986 e Velini \& Pitelli, 1991), sendo este o parâmetro de produção mais afetado (Durigan et al., 1983).

Para todas as classes de tamanho de vagens, um período de 10 dias de controle das plantas daninhas determinou uni número de vagens semelhante a testemunha no limpo. Contudo, houve decréscimos no número de vagens a partir de 70, 50 e 60 dias de convívio da cultura com a comunidade infestante, para as classes de tamanho de vagens com zero, um e dois grãos, respectivamente. O convívio da comunidade infestante com a cultura por até 100 dias não determinou a redução do núme ro de vagens com dois grãos em relação a testemunha no limpo. O número de vagens com quatro grãos não foi afetado por nenhum dos tratamentos testados, uma vez que a produção de vagens com quatro grãos não é característica da variedade OCEPAR 4 - Iguaçu.

Eaton et al. (1973) e Scroll \& Scheiber (1984) encontraram efeitos prejudiciais das plantas daninhas sobre o tamanho de vagens. Entretanto, no Brasil, MAIA et a!. (1982) não verificaram este tipo de resultados, provavelmente devido à cultivar, à densidade e composição da comunidade infestante, além das condições edafoclimáticas, uma vez que o trabalho foi conduzido em condições de cerrado.

Na Tabela 3 estão apresentados os dados médios de estande, altura de inserção da primeira vagem e o rendimento de grãos.

Um período de controle da comunidade infestante de apenas 10 dias foi o suficiente para que o estande da cultura fosse semelhante a testemunha no limpo. Decréscimos no estande somente foram observados na testemunha mantida no mato e quando o periodo de convivência foi de 100 dias, resultado este que corrobora os de (Rossi, 1985) e em parte os de (Velini \& Pitelli, 1991). Todavia, a redução no estande não foi observada por (Durigan et al., 1983).

Resultados diferenciados são devidos à pressão competitiva das espécies envolvidas, variedade e precipitação pluviométrica do local. Outro fator de grande influência é a capacidade que algumas plantas daninhas tem de sombrear a cultura, reduzindo sua capacidade fotossitética, como faz o capim-marmelada.

A altura das plantas de soja não foi afetada pelas plantas daninhas, resultado este semelhante aos obtidos por (Maia et al., 1982 e Patterson, 1985) e discordantes dos encontrados por (Eaton et al., 1973; Durigan et al., 1983 e Wulff, 1987). Já, Velini \& Pitelli (1991) verificaram que a matointerferência determinava um incremento na altura de plantas. $\mathrm{O}$ estiolamento das plantas foi observado neste trabalho somente em relação a altura de inserção da primeira vagem, determinado por um período de convivência de 70 dias ou mais.

Durigan et al. (1983) relatam que a altura de inserção da primeira vagem está relacionada com a competição por luz e a formação de flores na parte inferior da soja, pois o sombreamento ocasionado pelas plantas daninhas afeta a eficiência fotossintética das folhas basais, prejudicando o transporte e distribuição de carbohidratos. O capim-marmelada, por produzir muita biomassa e um dossel compacto de folhas sobre a soja, obstrui a passagem da luz, o que pode ter determinado o incremento da altura de inserção da primeira vagem.

Um período de 20 dias de controle das plantas daninhas ou de 30 dias de convívio após a germinação da cultura, ocasionou um rendimento de grãos semelhante a testemunha no limpo. De acordo com a terminologia de (Pitelli \& Durigan, 1984), o PTPI seria de 20 dias e o PAI de 30 dias.

A medida que o uso de herbicidas, principalmente residuais, ou controle cultural, tornam-se mais intensos na agricultura, as plantas daninhas tendem a ser selecionadas, 
TABELA 2 - Efeito de diferentes períodos de controle ou convivência das plantas daninhas sobre o número de vagens por planta e a distribuiçăo porcentual do número de grảos de soja, classificados em diferentes tamanhos de vagens. Cascavel, 1989/90. Média de 3 repetiçöes.

\begin{tabular}{|c|c|c|c|c|c|c|}
\hline Tratamento & $\begin{array}{l}\text { Número de } \\
\text { vagens/pt. }\end{array}$ & $\begin{array}{l}\text { Vagens com } \\
\text { zero grãos }\end{array}$ & $\begin{array}{l}\text { Vagens com } \\
\text { um grão }\end{array}$ & $\begin{array}{l}\text { Vagens com } \\
\text { dois gräos }\end{array}$ & $\begin{array}{l}\text { Vagens com } \\
\text { três grãos }\end{array}$ & $\begin{array}{l}\text { Vagens com } \\
\text { quatro grãos }\end{array}$ \\
\hline \multicolumn{7}{|l|}{ Dias Livre do mato } \\
\hline 1. 0 dias (test.mato) & $10,6 \mathrm{EF}$ & $55,1 \mathrm{~A}$ & $67,0 \mathrm{~A}$ & $49,7 \mathrm{E}$ & $27,3 \mathrm{~F}$ & 0,0 \\
\hline 2. 10 dias & $20,1 \mathrm{ABCD}$ & $6,1 \mathrm{DEF}$ & $17,7 \mathrm{DEF}$ & $86,0 \mathrm{ABC}$ & $90,3 \mathrm{ABCD}$ & 0,0 \\
\hline 3. 20 dias & $25,9 \mathrm{~A}$ & $1,0 \mathrm{G}$ & $15,0 \mathrm{EF}$ & $77,3 \mathrm{ABCD}$ & $109,0 \mathrm{ABCD}$ & 0,7 \\
\hline 4. 30 dias & $28,0 \mathrm{~A}$ & 2,0 EFG & $15,3 \mathrm{EF}$ & $69,3 \mathrm{ABCD}$ & $113,3 \mathrm{AB}$ & 0,7 \\
\hline 5. 40 dias & $26,6 \mathrm{~A}$ & 2,3 EFG & $12,7 \mathrm{EF}$ & $71,3 \mathrm{ABCD}$ & $112,0 \mathrm{AB}$ & 1,7 \\
\hline 6. 50 dias & $26,3 \mathrm{~A}$ & $0,7 \mathrm{G}$ & $9,0 \mathrm{~F}$ & $60,0 \mathrm{CD}$ & $120,3 \mathrm{~A}$ & 1,0 \\
\hline 7. 60 dias & $26,6 \mathrm{~A}$ & 2,0 EFG & $11,3 \mathrm{EF}$ & $69,7 \mathrm{ABCD}$ & $116,0 \mathrm{~A}$ & 1,0 \\
\hline 8. 70 dias & $26,0 \mathrm{~A}$ & $1,3 \mathrm{FG}$ & $9,3 \mathrm{~F}$ & $68,3 \mathrm{ABCD}$ & $120,0 \mathrm{~A}$ & 1,2 \\
\hline 9. 80 dias & $26,4 \mathrm{~A}$ & 2,3 EFG & $12,0 \mathrm{EF}$ & $75,3 \mathrm{ABCD}$ & $109,0 \mathrm{ABC}$ & 1,1 \\
\hline 10. 90 dias & $25,8 \mathrm{AB}$ & $1,3 \mathrm{FG}$ & $9,1 \mathrm{~F}$ & $67,0 \mathrm{ABCD}$ & $121,3 \mathrm{~A}$ & 1,3 \\
\hline 11. 100 dias & $22,3 \mathrm{ABC}$ & $2,7 \mathrm{EFG}$ & $10,0 \mathrm{~F}$ & $76,3 \mathrm{ABCD}$ & $110,0 \mathrm{AB}$ & 1,0 \\
\hline \multicolumn{7}{|c|}{ Dias de convívio com mato } \\
\hline 12. 0 dias (test.limpo) & $26,1 \mathrm{~A}$ & $2,0 \mathrm{EFG}$ & $11,0 \mathrm{EF}$ & $76,0 \mathrm{ABCD}$ & $110,7 \mathrm{AB}$ & 1,0 \\
\hline 13. 10 dias & $22,8 \mathrm{ABC}$ & $0,3 \mathrm{G}$ & $11,3 \mathrm{EF}$ & $75,3 \mathrm{ABCD}$ & $112,0 \mathrm{AB}$ & 0,7 \\
\hline 14. 20 dias & $24,8 \mathrm{AB}$ & $3,0 \mathrm{EFG}$ & $10,0 \mathrm{~F}$ & $75,7 \mathrm{ABCD}$ & $110,7 \mathrm{AB}$ & 0,7 \\
\hline 15. 30 dias & $25,1 \mathrm{AB}$ & $1,0 \mathrm{G}$ & $11,7 \mathrm{EF}$ & $69,0 \mathrm{ABCD}$ & $117,3 \mathrm{~A}$ & 0,7 \\
\hline 16. 40 dias & $26,2 \mathrm{~A}$ & 2,0 EFG & $21,3 \mathrm{CDE}$ & $89,7 \mathrm{AB}$ & $86,0 \mathrm{ABCD}$ & 0,7 \\
\hline 17. 50 dias & $21,6 \mathrm{ABC}$ & 2,7 EFG & $27,0 \mathrm{CD}$ & $93,7 \mathrm{~A}$ & $75,0 \mathrm{ABCD}$ & 0,0 \\
\hline 18. 60 dias & $16,8 \mathrm{BCDE}$ & $6,7 \mathrm{DE}$ & $31,0 \mathrm{C}$ & $93,0 \mathrm{~A}$ & 69,0 DEFG & 0,0 \\
\hline 19. 70 dias & $14,5 \mathrm{CDEF}$ & $8,7 \mathrm{D}$ & $42,3 \mathrm{~B}$ & $93,0 \mathrm{~A}$ & 55,7 DEDF & 0,0 \\
\hline 20. 80 dias & $12,1 \mathrm{DEF}$ & $10,3 \mathrm{D}$ & $53,0 \mathrm{~B}$ & $94,0 \mathrm{~A}$ & $42,7 \mathrm{EF}$ & 0,0 \\
\hline 21. 90 dias & $11,4 \mathrm{DEF}$ & $20,3 \mathrm{C}$ & $48,7 \mathrm{~B}$ & $88,0 \mathrm{ABC}$ & $43,0 \mathrm{EF}$ & 0,0 \\
\hline 22. 100 dias & $7,6 \mathrm{~F}$ & $55,0 \mathrm{~A}$ & $64,0 \mathrm{~A}$ & $63,0 \mathrm{BCD}$ & $24,0 \mathrm{~F}$ & 0,0 \\
\hline F. Bloco & $1,07^{\mathrm{ns}}$ & $2,90^{\mathrm{ns}}$ & $0,07^{\mathrm{ns}}$ & $1,78^{\mathrm{ns}}$ & $1,80^{\mathrm{ns}}$ & $1,24^{\mathrm{ns}}$ \\
\hline F. Tratamento & $14,13^{* *}$ & $291,49^{* *}$ & $91,73^{* *}$ & $5,31^{* *}$ & $18,61^{* *}$ & $0,91^{\text {ns }}$ \\
\hline C.V. $(\%)$ & 13,5 & 18,3 & 14,4 & 11,9 & 14,4 & 40,5 \\
\hline d.m.s. & 8,9 & 4,7 & 10,7 & 28,4 & 40,1 & 51,8 \\
\hline
\end{tabular}

Médias seguidas da mesma letra, nåo diferem estatisticamente entre si, pelo teste de Tukey $(\mathrm{P}>0,05)$.

test. - testemunha

pt. - plantas

C.V. - coeficiente de variaçăo

d.m.s. - diferença mínima significativa

ns - nåo significativo

** - significativo ao nível de $1 \%$ de probabilidade

levando a manutenção de um pequeno grupo de espécies. Este fato, determina mudanças nas relações de interferência entre a planta cultivada e a comunidade infestante.

Quando há a presença de uma espécie dominante, como no caso deste trabalho, podem ser encontrados valores maiores para o PAI e menores para o PTPI (Rossi, 1985 e Velini \& Pitelli, 1991). Quando um grupo de plantas daninhas é equilibrado em termos de número de indivíduos por espécie, são encontrados valores de PAI menores que os de PTPI (Garcia et al., 1981 e Durigan et al., 1983). 
TABELA 3 - Efeito de diferentes períodos de controle ou convivência das plantas daninhas sobre o estande, a altura da planta, a altura de inserção da primeira vagem e o rendimento de grãos de soja. Cascavel, 1989/90. Média de 3 repetiçôes.

\begin{tabular}{|c|c|c|c|c|}
\hline Tratamento & Estande & $\begin{array}{l}\text { Altura das plantas } \\
(\mathrm{cm})\end{array}$ & $\begin{array}{l}\text { Altura de inserção da } \\
\text { primeira vagem }(\mathrm{cm})\end{array}$ & $\begin{array}{c}\text { Rendimento } \\
(\mathrm{kg} / \mathrm{ha})\end{array}$ \\
\hline \multicolumn{5}{|l|}{ Dias Livre do mato } \\
\hline 1. 0 dias (test.mato) & $9,5 \mathrm{C}$ & 71,9 & $17,6 \mathrm{~A}$ & $104 \mathrm{H}$ \\
\hline 2. 10 dias & $23,4 \mathrm{~A}$ & 73,4 & $16,2 \mathrm{AB}$ & $1.667 \mathrm{CD}$ \\
\hline 3. 20 dias & $22,5 \mathrm{AB}$ & 72,9 & $15,4 \mathrm{ABCD}$ & $2.333 \mathrm{~A}$ \\
\hline 4. 30 dias & $24,4 \mathrm{~A}$ & 72,9 & $14,5 \mathrm{ABCD}$ & $2.384 \mathrm{~A}$ \\
\hline 5. 40 dias & $22,5 \mathrm{AB}$ & 71,2 & $14,8 \mathrm{ABCD}$ & $2.366 \mathrm{~A}$ \\
\hline 6. 50 dias & $21,2 \mathrm{AB}$ & 71,5 & $14,4 \mathrm{ABCD}$ & $2.500 \mathrm{~A}$ \\
\hline 7. 60 dias & $23,1 \mathrm{~A}$ & 74,6 & $14,6 \mathrm{ABCD}$ & $2.491 \mathrm{~A}$ \\
\hline 8. 70 dias & $21,9 \mathrm{AB}$ & 72,3 & 14,1 $\mathrm{ABCD}$ & $2.399 \mathrm{~A}$ \\
\hline 9. 80 dias & $22,7 \mathrm{AB}$ & 73,3 & $14,9 \mathrm{ABCD}$ & $2.441 \mathrm{~A}$ \\
\hline 10. 90 dias & $21,7 \mathrm{AB}$ & 71,1 & $14,3 \mathrm{ABCD}$ & $2.396 \mathrm{~A}$ \\
\hline 11. 100 dias & $21,2 \mathrm{AB}$ & 72,3 & $14,7 \mathrm{ABCD}$ & $2.440 \mathrm{~A}$ \\
\hline \multicolumn{5}{|l|}{ Dias de convívio com mato } \\
\hline 12. 0 dias (test.limpo) & $24,2 \mathrm{~A}$ & 72,3 & $16,2 \mathrm{AB}$ & $2.558 \mathrm{~A}$ \\
\hline 13. 10 dias & $21,6 \mathrm{AB}$ & 72,8 & $15,5 \mathrm{ABCD}$ & $2.400 \mathrm{~A}$ \\
\hline 14. 20 dias & $22,3 \mathrm{AB}$ & 71,6 & $15,8 \mathrm{ABC}$ & $2.345 \mathrm{~A}$ \\
\hline 15. 30 dias & $22,3 \mathrm{AB}$ & 72,3 & $15,0 \mathrm{ABCD}$ & $2.262 \mathrm{AB}$ \\
\hline 16. 40 dias & $21,4 \mathrm{AB}$ & 71,9 & $13,3 \mathrm{ABCD}$ & $1.752 \mathrm{BC}$ \\
\hline 17. 50 dias & $22,2 \mathrm{AB}$ & 71,3 & $10,8 \mathrm{D}$ & $1.153 \mathrm{DE}$ \\
\hline 18. 60 dias & $22,7 \mathrm{AB}$ & 75,7 & $11,0 \mathrm{CD}$ & $941 \mathrm{E}$ \\
\hline 19. 70 dias & $23,7 \mathrm{~A}$ & 75,1 & $11,6 \mathrm{BCD}$ & $862 \mathrm{EF}$ \\
\hline 20. 80 dias & $23,3 \mathrm{~A}$ & 75,0 & $13,9 \mathrm{ABCD}$ & $658 \mathrm{EFG}$ \\
\hline 21. 90 dias & $18,2 \mathrm{AB}$ & 76,0 & $15,3 \mathrm{ABCD}$ & $334 \mathrm{FGH}$ \\
\hline 22. 100 dias & $16,2 \mathrm{BC}$ & 75,3 & $15,8 \mathrm{ABC}$ & $171 \mathrm{GH}$ \\
\hline F. Bloco & $0,08^{\mathrm{ns}}$ & $2,18^{\mathrm{ns}}$ & $0,13^{\text {ns }}$ & $0,78^{\mathrm{ns}}$ \\
\hline F. Tratamento & $6,42^{* *}$ & $1,20^{\text {ns }}$ & $3,46^{* *}$ & $81,79^{* *}$ \\
\hline C.V. $(\%)$ & 10,3 & 3,1 & 10,5 & 9,4 \\
\hline d.m.s. & 6,9 & 7,1 & 4,8 & 521,0 \\
\hline
\end{tabular}

Médias seguidas da mesma letra, nāo diferem estatisticamente entre si, pelo teste de Tukey $(\mathrm{P}>0,05)$.

test. - testemunha

pt. - plantas

C.V. - coeficiente de variação

d.m.s. - diferença mínima significativa

ns - nảo significativo

** - significativo ao nível de $1 \%$ de probabilidade

\section{LITERATURA CITADA}

BLANCO, H.G.; OLIVERIRA, D.A.; ARAUJO, J.B.M.; GRASSI, N. Observações sobre o período em que as plantas dnainhas competem com a soja [Glycine max (L.) Merr]. O Biológico, v.39, n.2, p.21-35, 1973.

CARVALHO, F.T. Integração de práticas culturais e dosagens de herbicida aplicado em pós-emergência, no controle da soja [Glycine $\max$ (L.) Merrill]. Jaboticabal: FCAV/UNESP, 1993. 114p. Tese de Mestrado.
CHEMALE, V.M.; FLECK, N.G. Avaliação de cultivares de soja [Glycine $\max (L$.) Merrill] em competição com Euphorbia heterophylla sob três densidades e dois períodos de ocorrência. Planta Daninha, v.5, n.2, p.3645, 1982.

CHITAPONG, P. Competition and control of jimsoweed (Datura stramonium) in narrow and wide-row soybeans. Dissertation Abstracts International, Sciences and Engineering, v.44, n.12, p.360, 1986. 
COELHO, J.P.; RODRIGUES, J.J.V.; SEDIYAMA, T. Competição de plantas daninhas com a cultura da soja (Glycine max), cultivar sucupira. In: CONGRESSO BRASILEIRO DE HERBICIDAS E PLANTAS DANINHAS, 17, 1988, Piracicaba, SP. Resumos. Piracicaba: SBHED, 1988. p.58-59.

COELHO, J.P.; RODRIGUES, J.J.V.; SEDIYAMA, T. Competição de plantas daninhas com a cultura da soja, cultivar sucupira. In: CONGRESSO BRASILEIRO DE HERBICIDAS E PLANTAS DANINHAS, 18, 1991, Brasília, DF. Resumos. Brasilia: SBHED, 1991. P.

DURIGAN, J.C.; VICTORIA FILHO, R.; MATUO, T.; PITELLI, R.A. Periodos de matocompetição na cultura da soja [Glycine $\max ($ L. ) Merrill], cultivar Santa Rosa e IAC - 2. I. Efeitos sobre parâmetros de produção. Planta Daninha, v.6, n.2, p.86-100, 1983.

EATON, B.J.; FELTNER, K..C.; RUSS, O.G. Venice mallow competition in soybeans. Weed Science, v.21, n.2, p.89-94, 1973.

GARCIA, A.; GAllIERO, D.L.P.; TORRES, E. Determinação do periodo critico de competição de ervas daninhas com a cultura da soja. In: EMBRAPA/Centro Nacional de Pesquisas de Soja (Londrina, PR). Resultados de pesquisa de soja 1980/81. Londrina, 1981. p.140-145.

HENRY, W.T.; BAUMAN, T.T. Zone of competitive influence of two large seeded annual broadleaf weeds in soybeans. In: NORTH CENTRAL WEED CON TROL CONFERENCE, 40, 1985, Sant Louis.

HOWER, O.W.I.; OLIVER, L.R. Influence of soybean (Glycine max) row spacing on pitted morningglory (Ipomoea lacunosa) interference. Weed Science, v.35, n.2, p.185-193, 1987.

JACKSON, L.A.; KAPUSTA, G.; MASON, D.J.S. Effect of duration and type of natural weed infestations on soybeans yield. Agronomy Journal, v.77, n.5, p.725-729, 1985.

JORDAN Jr., J.H. Sicklepod (Cassia obtusifolia) competition with soybeans as influenced by row spacing, density, sowing date and herbicides. Dissertation Abstracts International, Sciences and Engineering, v.44, p.2034, 1985.

MAIA, A.C.; RESENDE, A.M.; LACA-BUENDIA, J.P. Efeito do espaçamento e população de plantas daninhas na cultura da soja [Glycine $\max ($ L.) Merrill] em solo de cerrado. In: SEMINÁRIO NACIONAL DE PESQUISA DE SOJA, 2, 1982, Londrina. Anais. Londrina: EMBRAPA/CNPSO, 1982. p.331-338.
MARTINS, C.C.; SILVA, W.R. Estudos de bancos de sementes do solo. Informativo AERATES, v.4, n.1, p.49-56, 1994.

MURDOCK, E.C.; BANKS, P.A.; TOLER, J.E. Shade development effects on pitted morningglory (Ipomoea lacunosa) interferences with soybeans (Glycine max). Weed Science, v.34, n.5, p.711-777, 1986.

NOGUSHI, K. Ecological study on light competition between upland crops and weeds. Bulletim National Agricultural Research Centre, v.1, p37-103, 1983.

OLIVER, L.R. Influence of soybean (Glycine max) planting date on velvetleaf (Abutilom theophrasti) competition. Weed Science, v.27, n.2, p.482-488, 1979.

PATTERSON, M.G. Comparison of small plot and large plot technique for soybean/weed competition studies. Dissertation Abstracts International, Sciences and Engineering, v.46, n.2, p.358, 1985.

PITELLI, R.A. Interferência das plantas daninhas em culturas agricolas. Informe Agropecuário, v.11, n.129, p.16-27, 1985.

PITELLI, R.A.; DURIGAN, J.C. Terminologia para periodos de controle e de convivência das plantas daninhas em culturas anuais e bianuais. In: CONGRESSO BRASILEIRO DE HERBICIDAS E PLANTAS DANINHAS, 15, 1984, Belo Horizonte, MG. Resumos. Piracicaba: SBHED, 1984.p37.

ROSSI, C.A. Efeitos de periodos de controle e de convivência de plantas daninhas na cultura da soja [Glycine max (L.) Merrill]. Jaboticabal: FCAV/ UNESP, 1985. 40p. Trabalho de Graduação em Agronomia.

SCHROLL, R.E.; SCHEIBER, M.M. Foxtail interference on soybean growth. In: NORTH CENTRAL WEED CONTROL CONFERENCE, 1982, India nápolis. Abstracts. 1982. p.55-56.

VELINI, E.D.; PITELLI, R.A. Avaliação dos efeitos de comunidades infestantes naturais, controladas por diferentes periodos, sobre a produtividade da cultura soja. II. Efeito sobre a produtividade da cultura e seus componentes. In: CONGRESSO BRASILEIRO DE HERBICIDAS E PLANTAS DANINHAS, 18, 1991, Brasilia, DF. Resumos. Brasilia: SBHED, 1991.p.24.

WULFF, R.D. Growth response of soybean (Glycine max) and sorghum (Sorghum bicolor) to an increase in density of Amaranthus dubius (O.) plants at two temperatures. Weed Research, v.27, n.2, p.'79-85, 1987.

WYSE, D.L.; YOUNG, F.L.; JONES, R.J. Influence of Jerusalem artichoke (Helianthus tuberosus) density and duration of interference on soybean (Glycine max) growth and yield. Weed Science, v.34, n.2, p.243-247, 1986. 